\title{
Local assembly of long reads enables phylogenomics of transposable elements in a polyploid cell line
}

\author{
Shunhua Han*,1, Guilherme B. Dias*, ${ }^{*, 1}$, Preston J. Basting* ${ }^{*}$ Raghuvir Viswanatha ${ }^{\ddagger}$, Norbert Perrimon ${ }^{\ddagger} \S$ and Casey M.

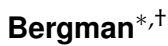 \\ ${ }^{*}$ Institute of Bioinformatics, University of Georgia, 120 E. Green St., Athens, GA, USA, ${ }^{\dagger}$ Department of Genetics, University of Georgia, 120 E. Green St., \\ Athens, GA, USA, ${ }^{\ddagger}$ Department of Genetics, Harvard Medical School, 77 Avenue Louis Pasteur, Boston, MA, USA, \$ Howard Hughes Medical Institute, Boston, \\ MA, USA, ${ }^{1}$ These authors contributed equally to this work.
}

\begin{abstract}
Animal cell lines cultured for extended periods often undergo extreme genome restructuring events, including polyploidy and segmental aneuploidy that can impede de novo whole-genome assembly (WGA). In Drosophila, many established cell lines also exhibit massive proliferation of transposable elements (TEs) relative to wild-type flies. To better understand the role of transposition during long-term animal somatic cell culture, we sequenced the genome of the tetraploid Drosophila S2R+ cell line using long-read and linked-read technologies. Relative to comparable data from inbred whole flies, WGAs for S2R+ were highly fragmented and generated variable estimates of TE content across sequencing and assembly technologies. We therefore developed a novel WGA-independent bioinformatics method called "TELR" that identifies, locally assembles, and estimates allele frequency of TEs from long-read sequence data (https://github.com/bergmanlab/telr). Application of TELR to a $\sim 130 x$ PacBio dataset for S2R+ revealed many haplotype-specific TE insertions that arose by somatic transposition in cell culture after initial cell line establishment and subsequent tetraploidization. Local assemblies from TELR also allowed phylogenetic analysis of paralogous TE copies within the S2R+ genome, which revealed that proliferation of different TE families during cell line evolution in vitro can be driven by single or multiple source lineages. Our work provides a model for the analysis of TEs in complex heterozygous or polyploid genomes that are not amenable to WGA and yields new insights into the mechanisms of genome evolution in animal cell culture.
\end{abstract}

KEYWORDS Drosophila, transposable elements, genome assembly, cell line, polyploidy

\section{Introduction}

Cell lines are commonly used in biological and biomedical research, however little is known about how cell line genomes evolve in vitro. For decades, it has been well-established that immortalized cell lines derived from plant or animal tissues often develop polyploidy or aneuploidy during routine cell culture (Ford and Yerganian 1958; Hink 1976; Ogura 1990; Bairu et al. 2011). More recently, the use of DNA sequencing has further revealed that segmental aneuploidy and other types of submicroscopic structural variation are widespread in cell lines (Zhang et al. 2010; Miyao et al. 2012; Adey et al. 2013; Lee et al. 2014; Nattestad et al. 2018; Ben-David et al. 2018; Zhou et al. 2019b,a; Liu et al. 2019; Han et al. 2021b). Together, these observations indicate that cells in culture often evolve complex genome architectures that deviate substantially from their original source material. Resolving the evolutionary processes that govern the transition from wild-type to complex cell line genome architectures is important for understanding the stability of cell line genotypes and the reproducibility of cell-line-based research. However, the complexity of cell line genomes can impose limitations on efforts to perform de novo whole-genome assembly (WGA) (Miller et al. 2018a,b; Nattestad et al. 2018) and thus limit the ability to study cell line genome structure and evolution using traditional WGA-based bioinformatics approaches.

Like many animal cell lines, Schneider-2 (S2) cells from the model insect Drosophila have undergone polyploidization 
bioRxiv preprint doi: https://doi.org/10.1101/2022.01.04.471818; this version posted January 4, 2022. The copyright holder for this preprint (which was not certified by peer review) is the author/funder, who has granted bioRxiv a license to display the preprint in perpetuity. It is made available under aCC-BY 4.0 International license.

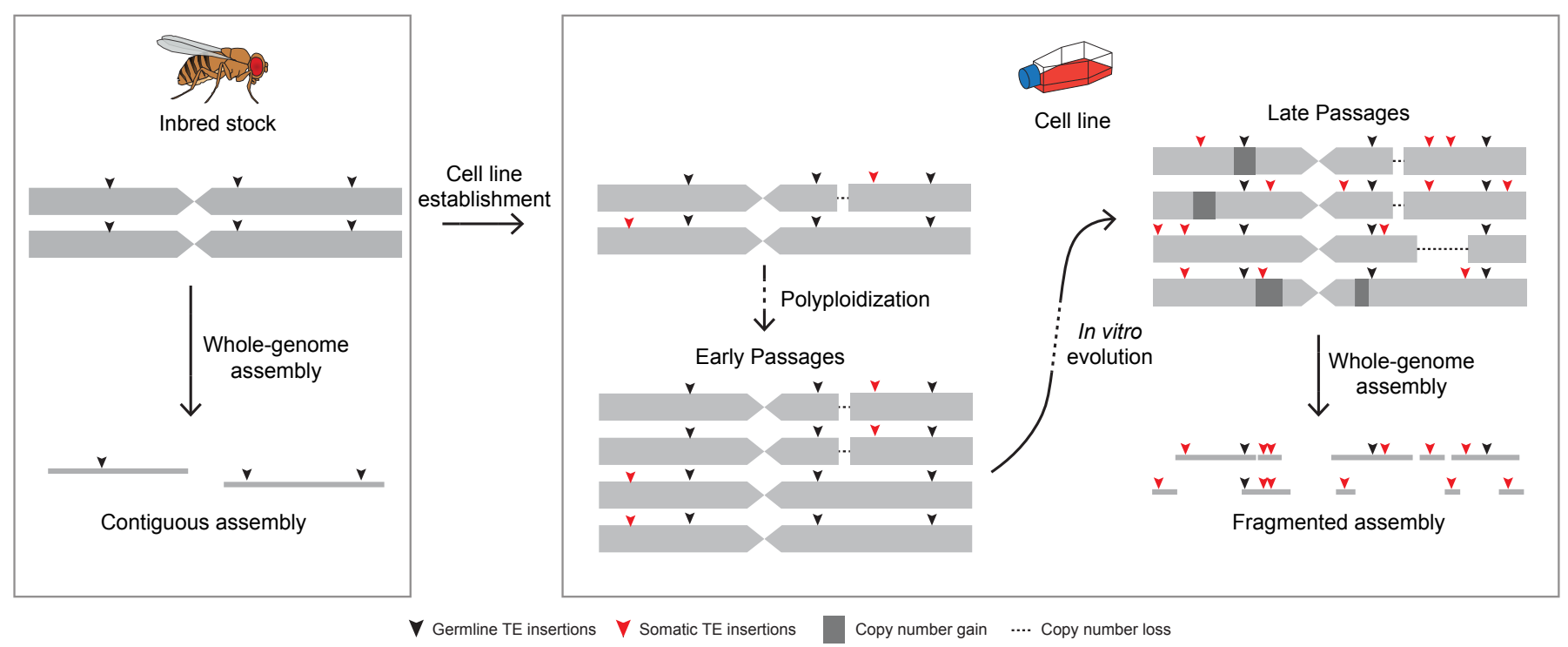

Figure 1 Genome architecture complexity hinders whole-genome assembly in long-term cultured cell lines. The inbred fly stock has diploid genome that includes homozygous variations, which allows contiguous whole-genome assembly (WGA). In comparison, cell lines established from inbred fly stock undergo polyploidization and accumulates heterozygous variations including segmental aneuploidy and haplotype-specific TE insertions during long-term culture. The complexity of polyploid genome with heterozygous variants may lead to highly fragmented WGA and as a result limit the utility of using WGA to study TE sequence evolution.

(Schneider 1972; Lee et al. 2014), and display substantial smalland large-scale segmental aneuploidy (Zhang et al. 2010; Lee et al. 2014; Han et al. 2021b). In addition, S2 and other Drosophila cell lines exhibit a higher abundance of transposable element (TE) sequences compared to whole flies (Potter et al. 1979; Ilyin et al. 1980; Rahman et al. 2015), with TE families that are abundant in S2 cells differing from those amplified in other Drosophila cell lines (Echalier 1997; Rahman et al. 2015; Han et al. 2021a; Mariyappa et al. 2021). However, little is known about TE sequence variation in S2 cells or other Drosophila cell lines. For example, it is generally unknown whether the proliferation of particular TE families in Drosophila cell lines is caused by one or more source lineages (Maisonhaute et al. 2007). The lack of understanding about TE sequences in Drosophila cell lines is mainly due to previous studies using short-read sequencing data (Rahman et al. 2015; Han et al. 2021a,b), which typically does not allow complete assembly of TE insertions or other structural variants (Alkan et al. 2011; Tattini et al. 2015; Kosugi et al. 2019; Zhao et al. 2021).

Recent advances in long-read DNA sequencing technologies have substantially improved the quality of WGAs, including a better representation of repetitive sequences such as TEs (Berlin et al. 2015). In Drosophila, long-read WGAs of homozygous diploid genomes such as those from inbred fly stocks can achieve high contiguity and permit detailed analysis of structural variation including TE insertions (Berlin et al. 2015; Chakraborty et al. 2018; Bracewell et al. 2019; Chang et al. 2019; Mohamed et al. 2020; Ellison and Cao 2020; Hemmer et al. 2020; Wierzbicki et al. 2021). However, successful WGA using long reads remains limited by complex genome features including polyploidy, heterozygosity, and high repeat content, all of which are present in cell lines such as Drosophila S2 cells (Schneider 1972; Potter et al. 1979; Ilyin et al. 1980; Zhang et al. 2010; Lee et al. 2014; Rahman et al. 2015; Han et al. 2021a). In fact, the state-of-the-art long-read assem- blies of wild-type diploid genomes still suffer from the presence of repeats and heterozygosity, which may result in assembly gaps and haplotype duplication artifacts (Rhie et al. 2021; Peona et al. 2021). Therefore, assembly of a complex Drosophila cell line genome is likely to result in substantially more fragmented WGAs than those generated from homozygous diploid fly stocks (Fig. 1), and this degradation of assembly quality could impact the subsequent analysis of TE sequences.

To gain better insight into the role of transposition during genome evolution in animal cell culture, here we sequenced the genome of a commonly-used variant of S2 cells, the S2R+ cell line (Yanagawa et al. 1998), using PacBio long-read and 10x Genomics linked-read technologies. As predicted, WGAs of S2R+ from long-read sequencing data were highly fragmented and yielded highly variable estimates of TE content using different assembly methods. To circumvent the limitations of WGA and characterize TE content in Drosophila cell lines, we developed a novel TE detection tool called TELR (Transposable Elements from Long Reads, pronounced "Teller") that can predict nonreference TE insertions based on a long-read sequence dataset, reference genome, and TE library. Importantly, TELR can detect haplotype-specific TE insertions, reconstruct TE sequences, and estimate intra-sample TE allele frequencies (TAFs) from complex genomes that are not amenable to WGA. We applied TELR to our PacBio long-read dataset for S2R+ and similar datasets for a geographically-diverse panel of $D$. melanogaster inbred fly strains from the Drosophila Synthetic Population Resource (DSPR) (Chakraborty et al. 2019). We discovered a large number of haplotype-specific TE insertions from a subset of LTR retrotransposon families in the tetraploid S2R+ cell line. We inferred that these haplotype-specific insertions came from somatic transposition events that occurred in vitro after initial cell line establishment and subsequent tetraploidization (Schneider 1972; Lee et al. 2014). We also performed phylogenomic analysis 
bioRxiv preprint doi: https://doi.org/10.1101/2022.01.04.471818; this version posted January 4, 2022. The copyright holder for this preprint (which was not certified by peer review) is the author/funder, who has granted bioRxiv a license to display the preprint in perpetuity. It is made available under aCC-BY 4.0 International license.

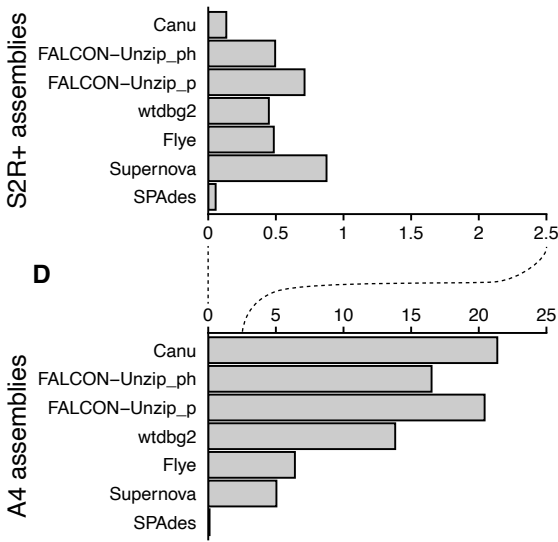

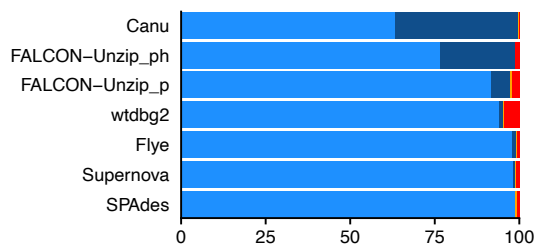

E

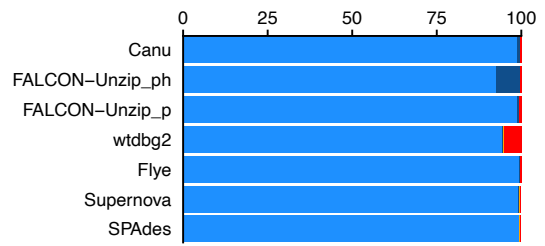

C

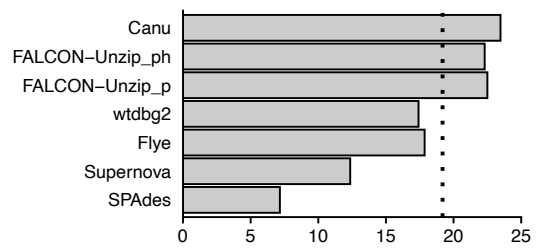

$\mathbf{F}$

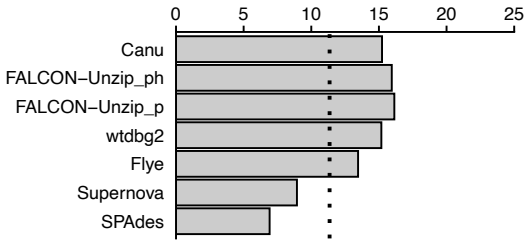

Figure 2 Lower contiguity, and higher BUSCO duplication and TE content in whole-genome assemblies of S2R+ compared to those from an inbred fly strain. (A) and (D) include contig (Canu, FALCON-Unzip, and wtdbg2) and scaffold (Flye, Supernova, and SPAdes) N50 values for S2R+ and A4 whole-genome assemblies, respectively. (B) and (E) include BUSCO (Benchmarking Universal Single-Copy Orthologs) analysis with the Diptera gene set from OrthoDBv10 on S2R+ and A4 assemblies, respectively. (C) and (F) include RepeatMasker estimates of TE content in WGAs of S2R+ and A4, respectively. Dotted lines in (C) and (F) represent RepeatMasker estimates of TE content from raw Illumina reads. "FALCON-Unzip_p" represents primary contigs, "FALCONUnzip_ph" represents primary contigs + haplotigs. Note that the scale bar is different in (A) and (D).

on the full-length TE sequences that were assembled by TELR, which revealed that amplification of TE families in Drosophila cell lines can be caused by activity of one or multiple source lineages. Together, our work provides a novel computational framework to study polymorphic TEs in complex heterozygous or polyploid genomes and improves our understanding of the mechanisms of genome evolution during long-term animal cell culture. and alternative haplotigs (Chin et al. 2016). Similar to the Canu assembly, combining the primary FALCON-Unzip assembly with alternative haplotigs ("FALCON-Unzip_ph") resulted a higher level of BUSCO duplication (Fig. 2B). This result suggested that many regions of the $\mathrm{S} 2 \mathrm{R}+$ genome contain haplotypespecific structural variants that can lead to secondary haplotigs (and haplotype-induced BUSCO duplication) in the Canu and Falcon-Unzip assemblies.

N50s for all S2R+ WGAs were less than $1 \mathrm{Mbp}$, which is more than ten-fold smaller than the size of assembled chromosome arms in the Drosophila reference genome (Hoskins et al. 2015). To assess how S2R+ cell line WGAs compared to those from whole flies of inbred stocks, we also generated WGAs for a highly inbred D. melanogaster strain called A4 using available PacBio long-read data (110x average depth) from Chakraborty et al. (2019) and a 10x Genomics linked-read dataset for A4 generated in this study (118X average depth) using identical assembly software and parameters as for S2R+. We found that WGAs for A4 have reference-grade contiguities and exhibit lower variation in levels of BUSCO duplication than WGAs for the S2R+ cell line (Fig. 2D,E; Table S2). Given that the A4 strain is diploid homozygous (Chakraborty et al. 2019), these results suggest that the highly fragmented WGAs for S2R+ are likely caused by polyploidy, aneuploidy, or heterozygosity in the S2R+ cell line genome rather than limitations of current sequencing or assembly methods.

In addition to assembly quality, estimates of TE content in WGAs varied substantially for both S2R+ and A4 (Fig. 2C,F; Table S1 and S2). Compared to unbiased estimates of TE content based on RepeatMasker analysis of unassembled short reads (dotted lines in Fig. 2C,F) (Sackton et al. 2009), long-read WGAs for both the S2R+ and A4 genomes typically gave similar or higher estimates of TE content, while short read WGAs always gave lower estimates. In particular, the Canu and Falcon-Unzip assemblies that we infer include alternative haplotigs gave the highest estimates of TE content relative to unassembled short 
bioRxiv preprint doi: https://doi.org/10.1101/2022.01.04.471818; this version posted January 4, 2022. The copyright holder for this preprint (which was not certified by peer review) is the author/funder, who has granted bioRxiv a license to display the preprint in perpetuity. It is made available under aCC-BY 4.0 International license.

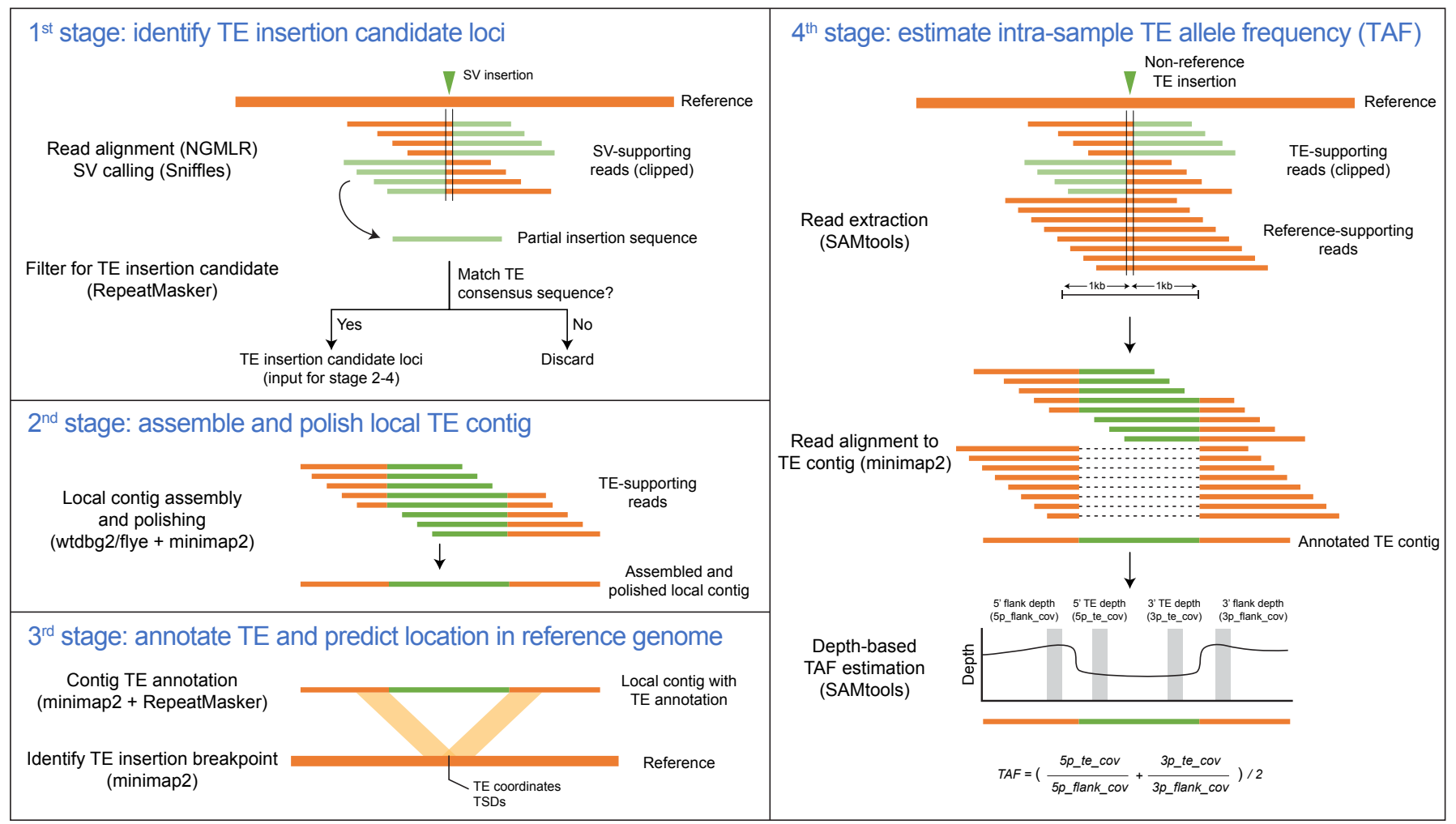

Figure 3 TELR workflow to predict non-reference TE and estimate intra-sample allele frequency. TELR is a non-reference transposable element (TE) detector from long read sequencing data. The TELR pipeline consists of four main stages. In the first stage, TELR aligns long reads to a reference and identify insertions using Sniffles (Sedlazeck et al. 2018). TELR then screens for nonreference TE insertion candidate locus by computing nucleotide similarity between partial insertion sequence provided by Sniffles and TE consensus sequences. In the second stage, TELR use SV-supporting reads from Sniffles to assemble and polish local contig using wtdbg2 (Ruan and Li 2020), flye (Kolmogorov et al. 2019), and minimap2 (Li 2018). In the third stage, The TE boundaries and family are annotated in the local contig using minimap2 and RepeatMasker, and the TE flanking sequences are used to determine the TE coordinates and target-site duplications by mapping to the reference genome with minimap2. In the fourth stage, TELR determines the intra-sample allele frequency of each TE insertion by extracting all reads in a $2 \mathrm{~kb}$ span around the insertion locus and aligning them to the TE contig. The mapped read depth over TE and flanking sequences are then used to calculate the intra-sample TE allele frequency (TAF).

read data, suggesting the possibility of haplotype-specific TE insertions in these assemblies. In addition to differences in overall TE content, we observed higher variation in the abundance of different TE families across sequencing and assembly technologies in WGAs for S2R+ (Fig. S1A) compared to A4 (Fig. S1B), indicating that WGA-based inferences about TE family abundance in S2R+ are highly dependent on sequencing and assembly technology. Despite this variation, higher estimates of overall TE content were observed in S2R+ WGAs relative to A4 WGAs for all sequencing or assembly technologies used (Fig. 2C,F; Table S1 and S2). However, because of the relatively poor quality and high variation in estimates of TE content among WGAs generated from S2R+ long-read and linked-read data, we concluded that an alternative WGA-independent approach that is better suited to the complexities of cell line genome architecture was necessary to reliably study TE content in S2R+ cells.

\section{A novel long-read bioinformatics method reveals TE families enriched in S2R+ relative to wild type Drosophila strains}

To circumvent the impact of fragmented WGAs on the analysis of TE content in complex cell line genomes, we developed a new TE detection method called "TELR" (Transposable Elements from Long Reads; https://github.com/bergmanlab/telr) that allows the identification, assembly, and allele frequency estimation of non-reference TE insertions using long-read data (Fig. 3). Briefly, TELR first aligns long reads to a reference genome to identify insertion variants using Sniffles (Sedlazeck et al. 2018). The general pool of insertion variants identified by Sniffles is then filtered by aligning putative insertion sequences to library of curated TE sequences to identify candidate TE insertion loci. For each candidate TE insertion locus, TELR then performs a local assembly using all reads that support the putative TE insertion event. Finally, TELR annotates TE sequence in each assembled contig, predicts the precise location of the TE insertion on reference coordinates, then remaps all reads in the vicinity of each insertion to the assembled TE contig to estimate TAF (see Materials and Methods for details).

Using TELR we identified 2,402 non-reference TE insertions 
bioRxiv preprint doi: https://doi.org/10.1101/2022.01.04.471818; this version posted January 4, 2022. The copyright holder for this preprint (which was not certified by peer review) is the author/funder, who has granted bioRxiv a license to display the preprint in perpetuity. It is made available under aCC-BY 4.0 International license.
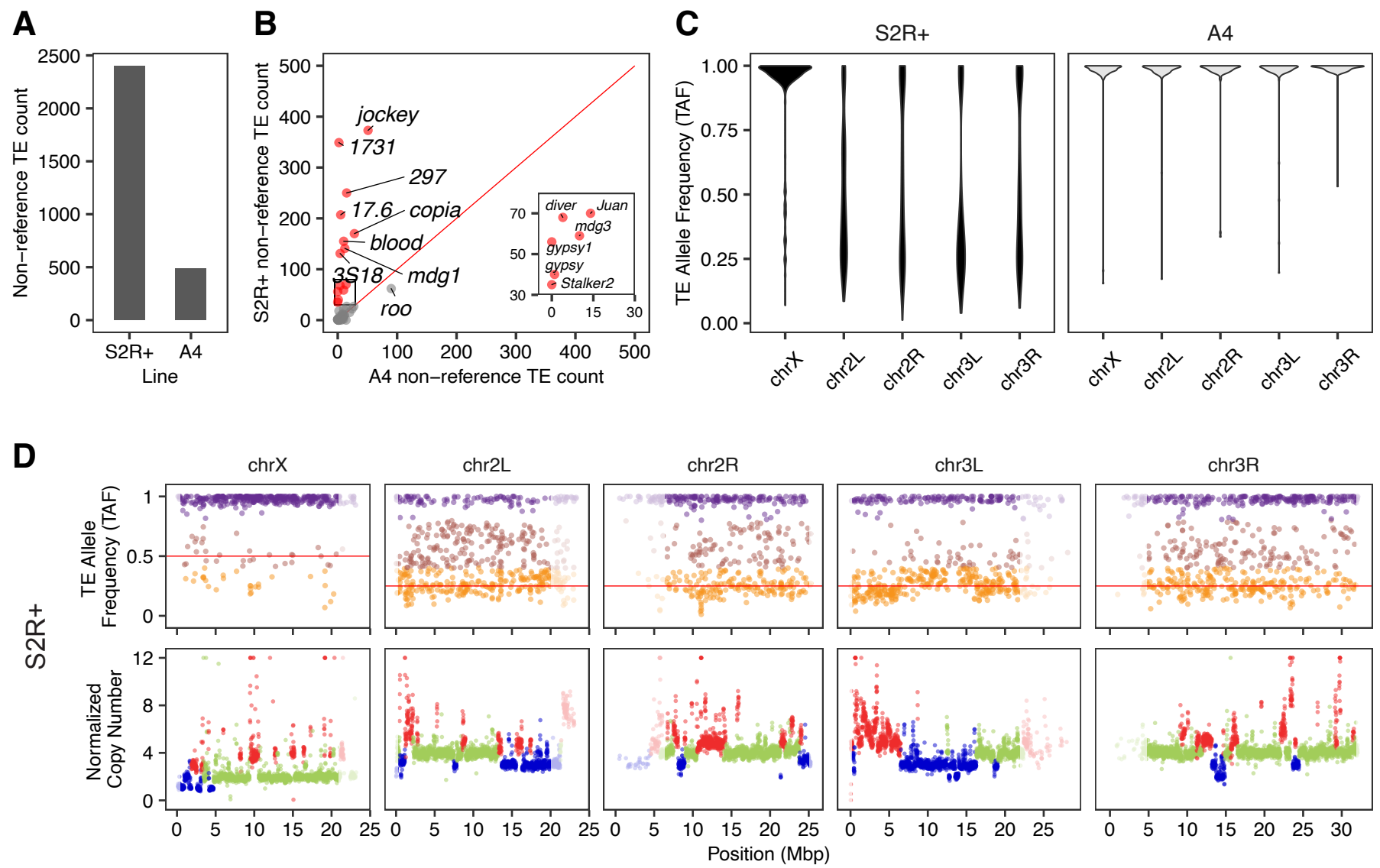

TE Allele Frequency (TAF)

- $>0.8 \quad 0.4-0.8 \quad \bullet<0.4$

Copy Number Variation (CNV) $\bullet$ gain

loss neutral

$\mathbf{E}$
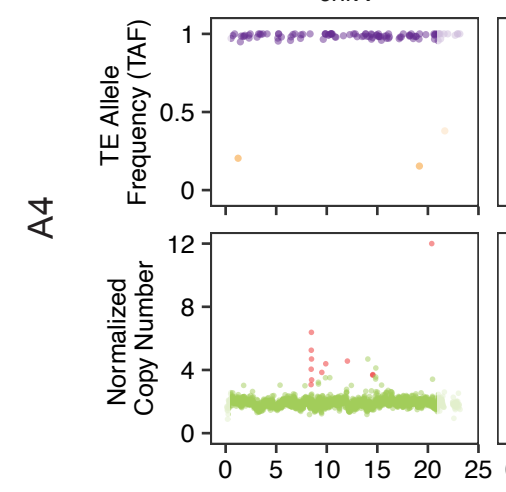

chr2L
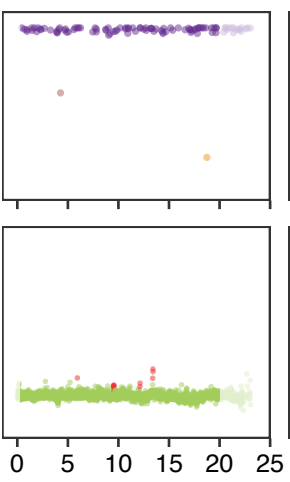

chr2R
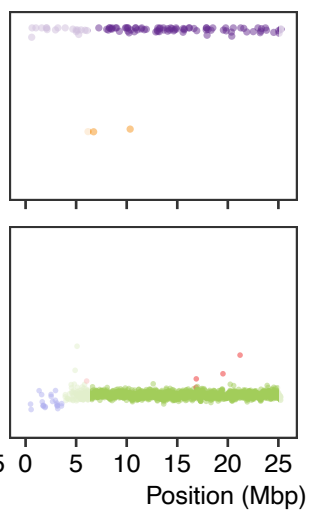

chr3L
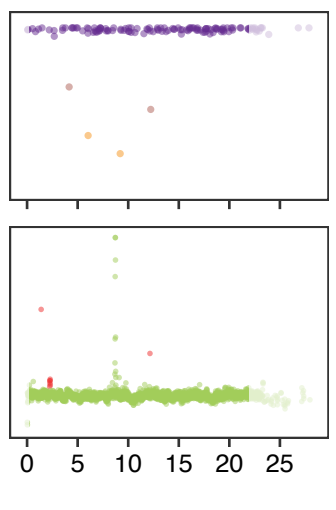

chr3R
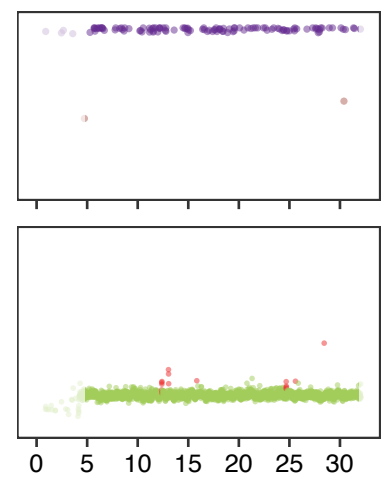

Figure 4 Long-read non-reference TE prediction with TELR reveals multiple families amplified during cell culture. A Total number of non-reference TE predictions made by TELR for S2R+ and A4. B Number of non-reference TE predictions made by TELR for S2R+ and A4 separated by families with the 14 most abundant families in S2R+ highlighted in red. The insert box is a zoomed plot that includes 6 abundant families in S2R+. C TAF distribution by chromosome arm for S2R+ and A4. D-E Genome-wide TAF and copy number profiles for S2R+ (D) and A4 (E). Low recombination regions are shaded in grey.

in euchromatic regions of the $\mathrm{S} 2 \mathrm{R}+$ genome, which is a $\sim 5$-fold increase relative to the number identified in A4 ( $n=490$; Fig. 4A). These overall differences in non-reference TE abundance between S2R+ and A4 are unlikely to be caused by variation in coverage and read length between the S2R+ and A4 datasets, as shown by analysis of read length and coverage normalized datasets for S2R+ and A4 (Fig. S2). Despite a drop in the number of predictions in the normalized data relative to the full dataset, TELR still predicted substantially more TEs in S2R+ compared to A4 at all coverage levels (Fig. S2). This analysis also revealed that, unlike A4 which plateaued in the number of non-reference TE insertions at a normalized read depth of 50X, detection of 
bioRxiv preprint doi: https://doi.org/10.1101/2022.01.04.471818; this version posted January 4, 2022. The copyright holder for this preprint (which was not certified by peer review) is the author/funder, who has granted bioRxiv a license to display the preprint in perpetuity. It is made available under aCC-BY 4.0 International license.

non-reference TEs in S2R+ is likely not saturated even at 75X. Therefore, in order to maximize TE prediction sensitivity, we used the complete non-normalized Pacbio data for S2R+ and all whole-fly strains in subsequent analyses.

Partitioning the number of non-reference TE insertions predicted by TELR in the complete S2R+ and A4 PacBio datasets by TE family revealed a subset of $14 \mathrm{TE}$ families that are enriched in S2R+ relative to A4 (Fig. 4B; Fig. S5). These S2R+-specific TE families consist mostly of long terminal repeat (LTR) retrotransposons with the exception of jockey and Juan, which are non-LTR retrotransposons (Fig. 4B; Fig. S5). The TE families revealed by TELR to be enriched in S2R+ relative to A4 were independently cross-validated using short-read sequences and two independent short-read TE detection methods (Fig. S3) (Han et al. 2021a; Zhuang et al. 2014).

We next used TELR to predict non-reference TEs in PacBio datasets for 13 geographically-diverse D. melanogaster inbred strains (including A4) from the DSPR project (Chakraborty et al. 2019). This analysis revealed that $S 2 R+$ has more non-reference TE insertions than any of the DSPR strains surveyed (range: 445658; Fig. S4). Partitioning TELR predictions by TE family reveals that only eight TE families account for $\sim 75 \%$ of non-reference insertions in S2R+, most of which are LTR retrotransposons (Fig. S4; Fig. S5). In comparison, $10-16$ TE families contribute $\sim 75 \%$ of all non-reference TE insertions in each of the DSPR strain, and they represent a more balanced distribution of LTR retrotransposons, non-LTR retrotransposons, and DNA transposons (Fig. S4; Fig. S5). We also observed strain-specific TE expansions, which we define as a greater than 3-fold increase in the number of non-reference TE insertions for a specific family relative to the mean values across all strains. For example, we see strain-specific expansions of $1360(\mathrm{n}=23$, mean=7.13) in A2 (from Colombia), hopper $(\mathrm{n}=114$, mean $=18.4)$ in A6 (from USA), as well as Doc $(n=113$, mean=26.5) and Quasimodo $(n=28$, mean=7) in B2 (from South Africa) (Fig. S5).

\section{Accurate estimation of intra-sample allele frequencies sup- ports haplotype-specific TE insertion after tetraploidy in the S2R+ genome}

An important feature of the TELR system is the ability to estimate the intra-sample allele frequency of non-reference TE insertions (Fig. 3), which allowed us to observe drastic differences between $\mathrm{S} 2 \mathrm{R}+$ and $\mathrm{A} 4$ in genome-wide TAF patterns. TE insertions in $\mathrm{S} 2 \mathrm{R}+$ display a wide range of allele frequencies, with a striking difference in TAF distributions on the $X$ chromosome relative to the autosomal arms (Fig. 4C; Fig. 4D). In contrast, non-reference TEs in the highly-inbred strain A4 (King et al. 2012) are mostly enriched at TAF values $\sim 1$ on all chromosome arms (Fig. 4C; Fig. $4 \mathrm{E})$. Broad-scale patterns of TAF distributions across the S2R+ and A4 genomes detected by TELR using long-read sequences were independently cross-validated using short-read sequences and two independent short-read TE detection methods (Fig. S6) (Han et al. 2021a; Zhuang et al. 2014).

Like A4, non-reference TEs in other DSPR strains are mostly homozygous with TAF values enriched at the expected value of $\sim 1$ for highly inbred diploid fly stocks (Fig. S7). However, our TELR analysis of DSPR datasets revealed two striking exceptions to this pattern. First, A2 displays mostly heterozygous TE insertions across chromosome arm 3R, which coincides with the presence of a known heterozygous chromosomal inversion in this strain $(\operatorname{In}(3 R) P)$ that prevents full inbreeding (King et al. 2012). Second, TAF values in A7 are enriched at $\sim 0.25$ and $\sim 0.75$ across the whole genome (Fig. S7). This TAF pattern is unusual since A7 is thought to be fully inbred and devoid of large chromosomal inversions (King et al. 2012). We hypothesized that the bimodal TAF profile in A7 could be indicative of contamination in the A7 data with PacBio reads from a different fly strain in the DSPR project. Indeed, intersecting TELR predictions between A7 and other DSPR strains revealed an unusually large number of non-referenece TE insertion overlaps between strains A7 and B3 (Table S3). Moreover, shared TE insertions between A7 and B3 have TAF enriched at $\sim 0.25$, which could be explained by $\sim 25 \%$ of the A7 dataset being contaminated with reads from B3 (Fig S8). Our inference of contamination in the A7 dataset with reads from another DSPR strain can also explain the observations that A7 has the highest number of non-reference TEs in our TELR analysis (Fig S4), and that the A7 WGA reported in Chakraborty et al. (2019) has the highest level of BUSCO duplication, longest assembly length, and most scaffolds of all DSPR strains in that study.

In S2R+, we observed a clear enrichment for TE insertions on the autosomes to have TAFs $\sim 0.25$ (Fig. 4C; Fig. 4D), which can be explained by haplotype-specific TE insertions that occurred after initial cell line establishment and subsequent tetraploidization (Fig. 5A) (Schneider 1972; Lee et al. 2014). In contrast to the autosomes, TE insertions on the $\mathrm{X}$ chromosome in S2R+ are enriched at TAFs $\sim 1$ (Fig. 4C; Fig. 4D). The $X$ chromosome in the tetraploid S2R+ genome has a baseline ploidy of two since the S2 lineage is thought to have been derived from a hemizygous male genotype (Lee et al. 2014). Thus, the enrichment of $X$-chromosome TE insertions with TAF $\sim 1$ could be explained by a recent loss of heterozygosity $(\mathrm{LOH})$ event in the $X$ chromosome of $\mathrm{S} 2 \mathrm{R}+$ through mitotic recombination. This explanation is plausible since a previous study has shown that copy-neutral LOH events in cell culture can shape TAF profiles over large genomic regions in Drosophila cell lines (Han et al. 2021a).

Assuming uniform copy number throughout the genome, haplotype-specific autosomal TE insertions that occured in the $\mathrm{S} 2 \mathrm{R}+$ after tetraploidy are expected to have TAFs at $\sim 0.25$. However, the extensive copy number variation observed in the S2R+ genome increases or decreases TAF estimates in affected segments relative to this expected value (Fig. 4D). Additionally, we observed many TE insertions on the S2R+ autosomes that have intermediate TAFs between 0.25 and 1.0, suggesting the possibility of other mechanisms besides haplotype-specific posttetraploid TE insertion to explain the observed TAF distribution. For example, ancestrally-heterozygous diploid TE insertions (either germline insertions in the Oregon-R lab strain that S2R+ was established from, or somatic insertions in the pre-tetraploid stage of S2) could have undergone mitotic recombination events in the post-tetraploid state changing one haplotype from TEpresent to TE-absent (Fig. 5B) (Han et al. 2021a). Assuming that ancestral heterozygous diploid TE insertions would be randomly distributed on the two different haplotypes of the Oregon- $R /$ pretetraploid state of $\mathrm{S} 2 \mathrm{R}+$, these alternative models can be differentiated since mitotic recombination in the post-tetraploid state would have the same probability of increasing or decreasing TE allele copy number (Fig. 5B), whereas haplotype-specific TE insertion would lead to an excess of alleles with a copy number of one (Fig. 5A).

To facilitate the interpretation of TAF values under varying copy number status and more rigorously test the "haplotypespecific post-tetraploid TE insertion" (Fig. 5A) vs "ancestral TE insertion and post-tetraploid mitotic recombination" (Fig. 5B) 
bioRxiv preprint doi: https://doi.org/10.1101/2022.01.04.471818; this version posted January 4, 2022. The copyright holder for this preprint (which was not certified by peer review) is the author/funder, who has granted bioRxiv a license to display the preprint in perpetuity. It is made available under aCC-BY 4.0 International license.

A Haplotype-specific post-tetraploid TE insertion

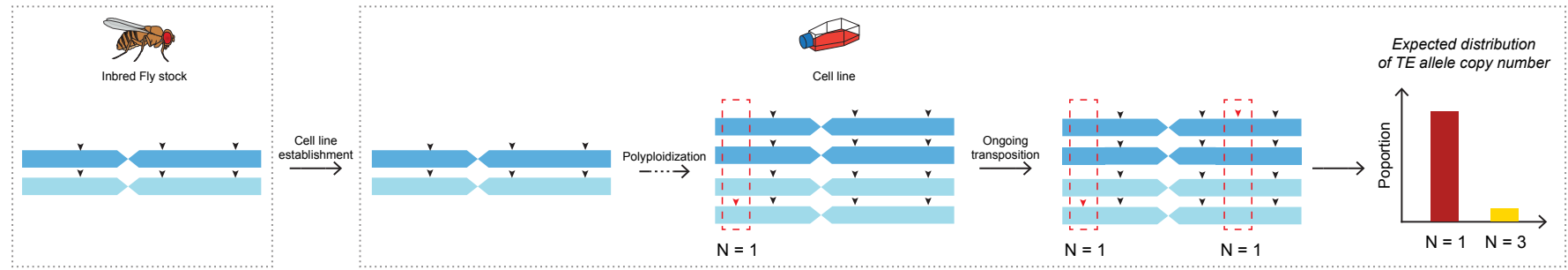

B Ancestral TE insertion and post-tetraploid mitotic recombination

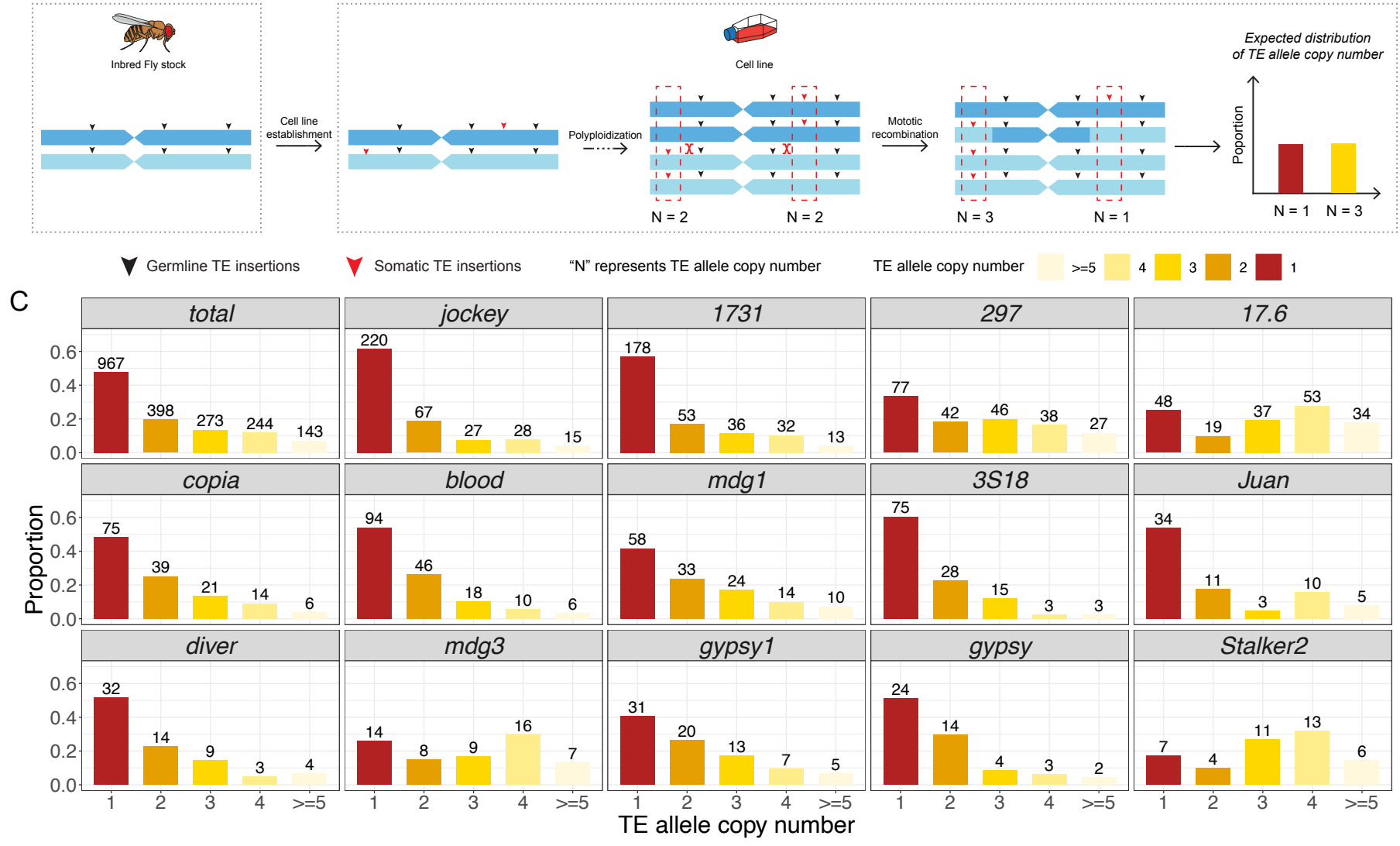

Figure 5 TE allele copy number distribution supports haplotype-specific TE insertion after tetraploidy in the S2R+ genome. A-B Two hypotheses that could explain the observation of haplotype-specific TE insertions in the tetraploid S2R+ genome. C Distribution on proportion of TE allele copy number for all TEs combined and for 14 TE families that are amplified in S2R+. The TE allele copy number is estimated based on TAF predicted by TELR and local copy number predicted by Control-FREEC (Boeva et al. 2012). The histogram is colorized based on TE allele copy number. The number above each bar represents number of TEs under each TE allele copy number category.

models, we developed a strategy to predict absolute TE allele copy number for non-reference TE on the autosomes. For each non-reference TE insertion, we multiplied TAF estimates generated by TELR by the local copy number estimated by ControlFREEC (Boeva et al. 2012) in regions flanking the TE insertion, then rounded to the nearest integer value. This procedure generated accurate predictions of TE allele copy number on synthetic tetraploid genomes (see Supplemental Text; Fig S9). Our analysis revealed that a significant proportion of non-reference TE insertions from the $14 \mathrm{TE}$ families that are amplified in S2R+ have a predicted TE allele copy number of one (Fig. 5C). Furthermore, we found that number of TEs with predicted TE allele copy number of one is significantly higher than the number of TEs with predicted TE allele copy number of three in autoso- mal regions of S2R+ overall (Fig. $5 \mathrm{C}$; chi-squared $=388.42, \mathrm{df}$ $=1$, p-value $<2.2 \mathrm{e}-16$ ) and for all but three S2R+-amplified TE families $(m d g 3$, Stalker $2,17.6)$. Thus, we conclude that the majority of insertions in TE families that are amplified in S2R+ are caused by haplotype-specific TE insertions that occurred after tetraploidization, rather than ancestral heterozygous insertions that were reduced in copy number after tetraploidization by mitotic recombination.

TE expansions in Drosophila cell culture can be caused by one or more source lineages

Haplotype-specific TE insertions that occurred after tetraploidization must have occurred somatically during cell culture, and thus provide a rich set of TE sequences to 
A

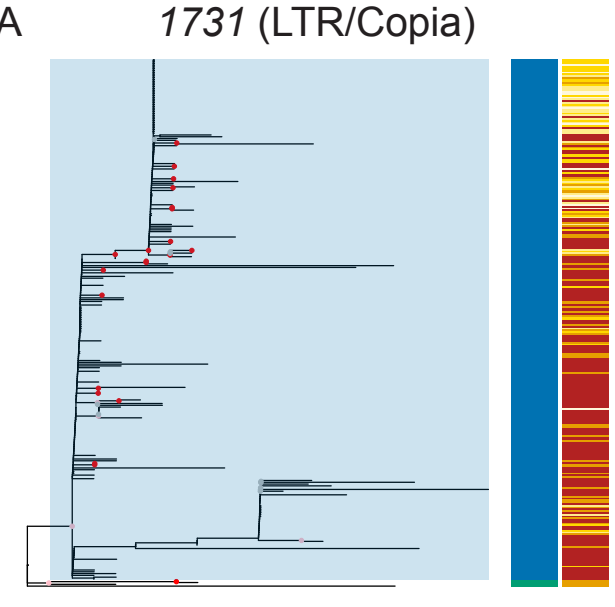

C jockey (LINE/Jockey)

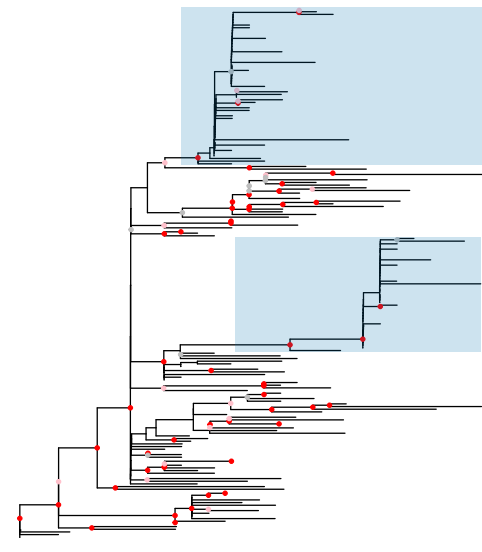

TE allele copy number
B 297 (LTR/Gypsy)

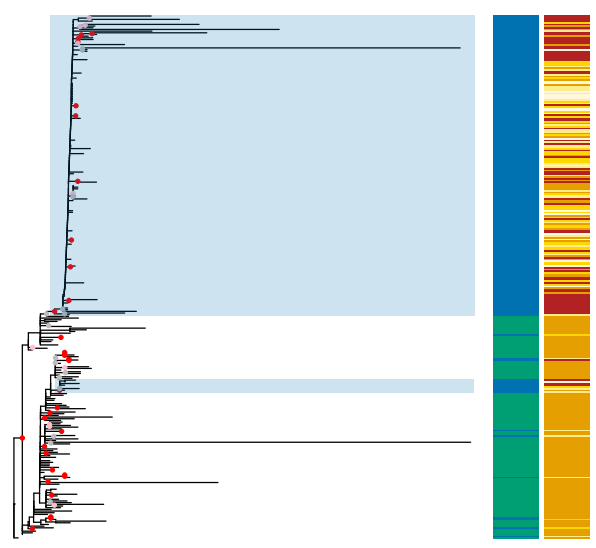

D Juan (LINE/Jockey)
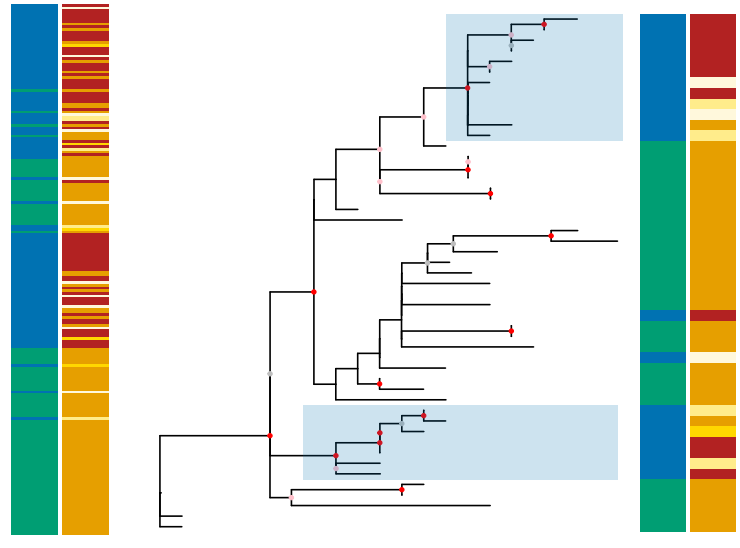

Figure 6 Single and multiple TE source lineage activation in S2R+ cell line. A-D Non-reference TE insertion sequences from S2R+ and 11 inbred Drosophila fly strains were predicted and assembled by TELR. Only high-quality full-length TE sequences in normal recombination autosomal regions were retained for this analysis (see Materials and Methods for details). TE sequences for each family were aligned using MAFFT (v7.487) (Katoh and Standley 2013). The multiple sequence alignments were used as input in IQ-TREE (v2.1.4-beta) (Minh et al. 2020) to build unrooted trees for 1731 (A), 297 (B), jockey (C) and Juan (D) elements using maximum likelihood approach. The sample source and TE allele copy number were annotated in the sidebars. Blue shading indicates TE expansion event in S2R+ from a single source lineage based on the following criteria: 1) All sequences should form a monophyletic clade, 2) The monophyletic clade should include at least three post-tetraploid cell-line-specific TE insertions, 3) The bootstrap support for the clade should be equal to or higher than $50 \%$, and 4) The proportion of post-tetraploid cell-line-specific TE insertions (i.e. TE allele copy number equal to one) within the clade should be equal to or higher than $20 \%$.

study how TE expansion events occur during in vitro genome 2 evolution. For example, it is generally unknown how many source copies or lineages contribute to proliferation of a TE family during cell culture. Using a PCR-based strategy, Maisonhaute et al. (2007) previously concluded that all non-reference insertions for the 1731 family in the S2 cell line were derived from a single, strongly-activated source copy. However, only a single TE family was surveyed and the number of 1731 new insertions identified was likely underestimated due to the limitations of the PCR-based strategy in this study. Moreover, it is difficult to conclude whether amplification is due to a single source copy or multiple closely-related copies from a single source lineage. To comprehensively test whether one or more source lineage is responsible for the amplification all $14 \mathrm{TE}$ families that expanded in S2R+ (Fig. 4B), we took advantage of TELR's ability to assemble non-reference TE sequences and constructed phylogenies using data from S2R+ and 13 whole-fly strains from the DSPR panel (Fig. 6; Fig. S10). Evaluation of TE sequences reconstructed by TELR using simulated datasets suggested that TELR produced high-quality local assemblies (see Supplemental Text; Fig. S11; Fig. S12), and thus can be reliably used to infer the sequence evolution of TEs amplified in the polyploid cell line genomes like S2R+.

Using the sequences of full-length TE insertions identified by TELR, we designed a set of criteria to identify TE expansion events in S2R+ that start from a single source lineage. First, the TE expansion event should be marked by a monophyletic clade in which $\geq 30 \%$ of TEs are enriched with post-tetraploid insertions in S2R+. Second, the candidate TE expansion clade should have at least $70 \%$ bootstrap support. Using these criteria, we annotated TE expansion events in the sequence phylogeny for each of the $14 \mathrm{TE}$ families that are enriched in S2R+ relative 
bioRxiv preprint doi: https://doi.org/10.1101/2022.01.04.471818; this version posted January 4, 2022. The copyright holder for this preprint (which was not certified by peer review) is the author/funder, who has granted bioRxiv a license to display the preprint in perpetuity. It is made available under aCC-BY 4.0 International license.

to A4 (Fig. 4B, TE families marked in red dots). We only used TE sequences in autosomes for this analysis, given that TE allele copy number distribution in Chromosome $\mathrm{X}$ is different from the autosomes presumably due to an $\mathrm{LOH}$ event after tetraploidy (see above). We identified a single TE expansion clade for TE families such as 1731, gypsy1, diver, gypsy, mdg3, and Stalker2 (Fig. 6; Fig. S10), suggesting that the TE expansion events in the S2R+ cell line for these families came from a single source lineage. We also identified multiple TE expansion clades for TE families such as jockey, Juan, copia, 3S18, and mdg1 (Fig. 6; Fig. S10), suggesting multiple source lineages contribute to the amplification of these families in S2R+. Together, our results revealed that TE expansions in S2R+ can be caused by single or multiple source lineages, and that the pattern of source lineage activation in somatic cell culture is TE family-dependent (Fig. 6; Fig. S10).

\section{Discussion}

Here we report new long-read and linked-read sequence data and develop a novel bioinformatics tool to study the role of transposition during long-term in vitro evolution of an animal cell line. Our finding that the complexities of Drosophila S2R+ genome architecture preclude the ability to accurately study TE content using long-read or linked-read WGAs motivated the development of a WGA-independent TE detection system called TELR, which can identify, locally assemble, and estimate allele frequency of TEs from long-read sequence data. Our work provides new tools and approaches to study TE biology in complex heterozygous or polyploid genomes found in many other animal cell lines (Lee et al. 2014; Nattestad et al. 2018; Talsania et al. 2019) as well as natural fungal and plant genomes (Todd et al. 2017; Meyers and Levin 2006).

Several related WGA-independent bioinformatic methods have recently been developed to detect non-reference TEs using long reads (Disdero and Filee 2017; Jiang et al. 2019; Zhou et al. 2020; Ewing et al. 2020; Chu et al. 2021; Kirov et al. 2021). These methods use a variety of strategies for TE detection and generate different information for predicted non-reference TEs. Importantly, none of these previously-reported methods for TE detection using long reads can estimate intra-sample TAF, a feature that we implemented in TELR specifically to identify haplotype-specific TE insertions and which enabled our analysis of post-tetraploidy somatic transposition in S2R+. Furthermore, TELR is the only WGA-independent long-read detection tool that outputs a polished assembly of the TE locus, providing a high-quality sequence of both the TE its flanking regions. The polishing step in TELR is especially important to improve sequence quality when using long-read assemblers such as wtdbg2 (Ruan and Li 2020) that do not error correct reads prior to the assembly step. High-quality sequences of predicted TE insertions generated by TELR allowed us to gain the first general insight into the sequence variation underlying TEs proliferation in an animal cell line.

Using the TELR system, we found a significantly higher number of non-reference TEs in S2R+, a sub-line of Drosophila S2 cell line, compared to whole fly of highly inbred strain from the DSPR project. The increased TE allele copy number in S2R+ relative to wild type flies is mainly contributed by a subset of mainly LTR and a few non-LTR retrotransposon families. Notably, TE families identified as enriched in S2R+ by TELR using long-read sequences were also detected as having high activity at some point during the history of S2 cell line evolution in an

independent analysis of short-read sequences for multiple sublines of S2 cells by Han et al. (2021b), providing cross-validation for both approaches. In addition, TELR predicted that a significant proportion of the non-reference TE insertions identified in $\mathrm{S} 2 \mathrm{R}+$ have TE allele copy number of one, which we interpreted as haplotype-specific somatic insertions that occurred after S2R+ cells became tetraploid, subsequent to the initial establishment of the original S2 cell line (Schneider 1972). This interpretation is consistent the main conclusion from Han et al. (2021b) that TE amplification in Drosophila S2 cells is an ongoing, episodic process rather than being driven solely by an initial burst of transposition dureing cell line establishment. Finally, the phylogenomic analysis using TELR-assembled sequences for TE families enriched in S2R+ suggested that the TE expansion in cell culture could come from a single or multiple source lineages, providing the first general insight into the sequence evolution of TE family expansions in animal cell culture.

\section{Materials and Methods}

\section{Cell culture}

An initial sample of S2R+ cells, which we define as passage 0 , was obtained from a routine freeze of cells made by the Drosophila RNAi Screening Center (DRSC). Cells from passage 0 were defrosted and recovered in Schneider's Drosophila medium (Thermo) containing 10\% FBS (Thermo) and 1X PenicillinStreptomycin (Thermo), then expanded continually for two additional passages in T75 flasks. Aliquots of cells from passage 3 flasks were frozen, and the remaining cells were expanded to 10 T75 flasks (passage 4A). Passage 4A cells were pooled and harvested to make DNA for PacBio libraries. A frozen stock was defrosted and expanded for two additional passages (passages 4B-5B). Passage 5B cells were harvested to make DNA for 10x Genomics libraries. The provenance of the cell line samples used in this study is depicted in Fig. S13.

\section{Fly stocks}

A stock of D. melanogaster strain A4 from the Drosophila Synthetic Population Resource (DSPR) (King et al. 2012) was obtained from Stuart Macdonald (University of Kansas) and reared on Instant Drosophila Medium (Carolina Biological, Cary NC) until DNA extraction.

\section{PacBio library preparation and sequencing}

Cells from ten confluent T75 flasks from passage 4A were scraped into a $15 \mathrm{~mL}$ Falcon tube and centrifuged at $300 \mathrm{xg}$ for $3 \mathrm{~min}$. The pellet was washed in $10 \mathrm{~mL}$ of $1 \mathrm{X}$ PBS, then resuspended in $7 \mathrm{~mL}$ of $1 X$ PBS containing $35 \mathrm{uL}$ of $10 \mathrm{mg} / \mathrm{mL}$ RNAse A (Sigma). $200 \mathrm{uL}$ of resuspended cells were aliquoted to $32 \mathrm{Ep}-$ pendorf tubes containing $200 \mathrm{uL}$ of buffer AL from the Qiagen Blood \& Tissue kit, mixed gently by inversion, and incubated at $37^{\circ} \mathrm{C}$ for $30 \mathrm{~min}$. $20 \mathrm{uL}$ of Proteinase K solution from the Qiagen Blood \& Tissue kit was then added to each tube and mixed gently by inversion. One volume of phenol:chloroform:isoamyl alcohol (24:24:1) was then added and inverted gently to mix for $1 \mathrm{~min}$. Tubes were then spun for $5 \mathrm{~min}$ at 21,000 x g. $180 \mathrm{uL}$ of the upper aqueous phase were then removed from each tube, and pairs of tubes were combined. $400 \mathrm{uL}$ of chloroform was then added to each of the 16 tubes, shaken for $1 \mathrm{~min}$ to mix, and spun at max speed for $5 \mathrm{~min}$. The top $300 \mathrm{uL}$ was removed and pairs of tubes were combined. $600 \mathrm{uL}$ of chloroform was added to each of the eight tubes, gently inverted 10 times to mix, 
bioRxiv preprint doi: https://doi.org/10.1101/2022.01.04.471818; this version posted January 4, 2022. The copyright holder for this preprint (which was not certified by peer review) is the author/funder, who has granted bioRxiv a license to display the preprint in perpetuity. It is made available under aCC-BY 4.0 International license.

and then spun at max speed for $5 \mathrm{~min} .400 \mathrm{uL}$ of the aqueous phase was removed and pairs of tubes were combined. $1 / 10$ volume of $3 \mathrm{M} \mathrm{NaOAc}$ was added to each of the four tubes, the remained of the tube was filled with absolute ethanol and then placed at $-20^{\circ} \mathrm{C}$ overnight. Tubes were then spun $21,000 \times \mathrm{g}$ at $4{ }^{\circ} \mathrm{C}$ for $15 \mathrm{~min}$, and the supernatant was decanted over paper towels. $70 \%$ ethanol was then added to tubes, the pellet was gently resuspended with a P1000 tip, and then placed on ice for $10 \mathrm{~min}$. Tubes were then spun $21,000 \times \mathrm{g}$ at $4{ }^{\circ} \mathrm{C}$ for $15 \mathrm{~min}$, and the supernatant was decanted over paper towels. The pellet was then resuspended in $50 \mathrm{uL}$ of Buffer EB from the Qiagen Blood \& Tissue kit, and gently pipetted with a P200 tip 5 times to resuspend. Purified S2R+ DNA was then used to generate PacBio SMRTbell libraries using the Procedure \& Checklist $20 \mathrm{~kb}$ Template Preparation using BluePippin Size Selection protocol. The SMRTbell library was sequenced using 31 SMRT cells on a PacBio RS II instrument with a movie time of 240 minutes per SMRT cell, generating a total of $3,510,012$ reads ( $\sim 28.5 \mathrm{Gbp})$.

\section{0x Genomics library preparation and sequencing}

Genomic DNA extraction followed the 10x "Salting Out Method for DNA Extraction from Cells" protocol (https://support. 10xgenomics.com/permalink/5HODz33gmQOea02iwQUOiK) adapted from Miller et al. (1988). Genomic DNA for D. melanogaster strain A4 linked-read library was obtained from a single female fly following the 10x Genomics recommended protocol for DNA purification from single insects (https://support. 10xgenomics.com/permalink/7HBJeZucc80CwkMAmA4oQ2).

Purified DNA was precipitated by addition of $8 \mathrm{~mL}$ of ethanol and resuspended in TE buffer and size was analyzed by TapeStation (Agilent) prior to library preparation. Linked-read libraries were then prepared for both S2R+ and A4 after DNA size selection with BluePippin to remove fragments shorter than $15 \mathrm{~kb}$. Libraries were prepared following the 10x Genomics Chromium Genome Reagent Kit Protocol v2 (RevB) using a total DNA input mass of $0.6 \mathrm{ng}$ for each sample. The linked-read libraries were sequenced on an Illumina NextSeq 500 instrument mid-output flow cell with $150 \mathrm{bp}$ paired-end layout, generating $95,280,430$ reads for S2R+ ( 13.3 Gbp) and 127,009,398 reads for A4 ( 17.7 Gbp).

\section{Whole-genome assembly and QC}

Raw PacBio reads from S2R+ (generated here; SRX7661404) and A4 from Chakraborty et al. (2018) (SRX4713156) were independently used as input for whole-genome assembly with Canu (v2.1.1; genomeSize $=180 \mathrm{~m}$ corOutCoverage $=200$ "batOptions=dg 3 -db 3 -dr 1 -ca 500 -cp 50" -pacbio-raw), FALCON-Unzip $(\mathrm{pb}$-falcon v0.2.6; seed coverage $=30$, genome_size $=180000000)$, wtdbg2 v2.5 (-x rs -g 180m), and Flye (v2.8.2) (Chin et al. 2016; Koren et al. 2017; Kolmogorov et al. 2019; Ruan and Li 2020). The reads were re-aligned to the resulting assemblies with pbmm2 (v1.3.0; --preset SUBREAD --sort) and the assemblies were polished with the Arrow algorithm from GenomicConsensus (v2.3.3) using default parameters. FALCON-Unzip performs read re-alignment and Arrow polishing automatically as part of its phasing pipeline.

10x Genomics linked-reads generated here were used as input for whole-genome assembly with Supernova (v2.1.1) for S2R+ (--maxreads $=61508497)$ and A4 (--maxreads $=77907944)$ (Weisenfeld et al. 2017). The optimal --maxreads parameter was calculated by Supernova in a previous run to avoid excessive coverage. Supernova assemblies were exported in pseudohap2 format and pseudo-haplotype1 was analyzed.

10x Genomics reads from S2R+ and A4 were also barcodetrimmed with LongRanger (v2.2.2; basic pipeline) (Zheng et al. 2016) to create standard paired-end reads as input to SPAdes (v3.15.0) using default parameters (Bankevich et al. 2012).

All assemblies were filtered to remove redundancy using the sequniq program from GenomeTools (v1.6.1) (Gremme et al. 2013). General assembly statistics were calculated with the stats.sh utility from BBMap (v38.83) (Bushnell 2014). Assembly completeness was assessed with BUSCO (v4.0.6) (Simao et al. 2015; Waterhouse et al. 2018) and the Diptera ortholog set from OrthoDB (v10) (Kriventseva et al. 2019).

\section{Assessment of overall TE content}

Transposable elements were annotated in all WGAs with RepeatMasker (v4.0.7; -s -no_is -nolow -x -e ncbi) (https://www. repeatmasker.org/RepeatMasker/) using v10.2 of the curated library of $D$. melanogaster canonical TE sequences (https://github. com/bergmanlab/transposons). TE abundance was calculated from RepeatMasker .out.gff files as the percentage of bases masked in each assembly.

Barcode-trimmed linked-reads were also used as an assemblyfree estimate of TE content in S2R+ and A4. Reads were filtered for adapters and low quality bases, and trimmed to $100 \mathrm{bp}$ using fastp (v0.20.0; --max_len1 100 --max_len2 100 -length_required 100) (Chen et al. 2018). A random sample of 5 million read pairs (10 million reads) was extracted for each dataset using seqtk (v1.3; -s2) (https://github.com/lh3/seqtk) and masked using RepeatMasker (v4.0.7; -s -no_is -nolow -x -e ncbi) and the D. melanogaster canonical TE set (v10.2; https: //github.com/bergmanlab/transposons). Abundance for each TE family was calculated as the percentage of read bases that were RepeatMasked.

\section{Detection of non-reference TE insertions using long reads}

The TELR pipeline consists of four main stages: (1) general SV detection and filter for TE insertion candidate, (2) local reassembly and polishing of the TE insertion, (3) identification of TE insertion coordinates, and (4) estimation of intra-sample TE insertion allele frequency.

In stage 1, long reads are aligned to the reference genome using NGMLR (v0.2.7) (Sedlazeck et al. 2018). The alignment output in BAM format is provided as input for Sniffles (v1.0.12) to detect structural variations (SVs) (Sedlazeck et al. 2018). TELR then filters for TE insertion candidates from SVs reported by Sniffles using following criteria: 1) The type of SV is an insertion, 2) The insertion sequence is available, and 3) The insertion sequences include hits from user provided TE consensus library using RepeatMasker (v4.0.7; http://www.repeatmasker.org/).

In stage 2, reads that support the TE insertion candidate locus based on Sniffles output are used as input for wtdbg2 (v2.5) to assemble local contig that covers the TE insertion for each TE insertion candidate locus (Ruan and Li 2020). The local assemblies are then polished using minimap2 (v2.20) (Li 2018) and wtdbg2 (v2.5) (Ruan and Li 2020).

In stage 3, TE consensus library is aligned to the assembled TE insertion contigs using minimap2 and used to define TEflank boundaries. TE region in each contig is annotated with family info using RepeatMasker (v4.0.7). Sequences flanking the TE insertion are then re-aligned to the reference genome using minimap2 to determine the precise TE insertion coordinates and target site duplication (TSD). 
In stage 4, raw reads aligned to the reference genome are extracted within a $1 \mathrm{~kb}$ interval on either side of the insertion breakpoints initially defined by Sniffles. The reads are then aligned to the assembled polished contig to identify reads that support the non-reference TE insertion and reference alleles, respectively, in following steps: 1) Reads are aligned to the forward strand of the contig, 5' flanking sequence depth (5p_flank_cov) and 5' TE depth (5p_te_cov) are calculated. 2) Reads are aligned to the reverse complement strand of the contig, 5' flanking sequence depth (3p_flank_cov) and 5' TE depth (3p_te_cov) are calculated. 3) The TE allele frequency is estimated as (5p_te_cov $\left./ 5 p \_f l a n k \_c o v+3 p \_t e \_c o v / 3 p \_f l a n k \_c o v\right) / 2$.

TELR (v0.2; revision bb90a5) was applied to the S2R+ PacBio dataset and to a panel of 13 D. melanogaster strains from the Drosophila Synthetic Population Resource (DSPR) (Bioproject ID PRJNA418342) (Chakraborty et al. 2019). The mapping reference used was release 6 of the D. melanogaster reference genome (chr2L, chr2R, chr3L, chr3R, chr4, chrX, chrY, chrM) (Hoskins et al. 2015) and the TE library was v10.2 of the D. melanogaster canonical TE sequence library (https://github.com/bergmanlab/transposons/blob/master/ releases/D_mel_transposon_sequence_set_v10.2.fa).

We used BEDTools (v2.29.0) (Quinlan and Hall 2010) to investigate the possibility of contamination of sample A7 with another strain by intersecting TE predictions between A7 and all other DSPR strains. calculated the ratio between each TELR sequence length and the corresponding canonical sequence length. Next, we filtered TELR sequences for full-length copies using a 0.75-1.05 ratio cutoff for 297 and 0.95-1.05 ratio cutoff for other TE families. 6) Only sequences with both 5' and 3' flanks mapped to reference genome were included. 7) Only sequences from TE insertions with TAF estimated by TELR were included.

TELR sequences from each family were aligned with MAFFT (v7.487) (Katoh and Standley 2013). The multiple sequence alignments (MSAs) were filtered by trimAI (v1.4.rev15; parameters: -resoverlap 0.75 -seqoverlap 80 ) to remove spurious sequences. The filtered MSAs were used as input to IQ-TREE (v2.1.4-beta; parameters: -m GTR+G -B 1000) (Minh et al. 2020) to generate maximum likelihood trees.

\section{Data Availability}

PacBio and 10x Genomics whole genome sequences generated in this project are available in the NCBI SRA database under accession PRJNA604454. WGAs of long-read and linked-read sequence data for the S2R+ and A4 genomes are available in the EBI BioStudies database under accession S-BSST752. Datasets of TE insertions in the S2R+ and DSPR genomes predicted by TELR are available as Supplemental File 1. Datasets of TE insertions in the S2R+ and A4 genomes predicted by TEMP and ngs_te_mapper2 are available as Supplemental File 2. Multiple sequence alignments of TE insertion sequences identified by TELR in the S2R+ and DSPR genomes are available as Supplemental File 3. Tree files for phylogenies of TE insertion sequences identified by TELR in the S2R+ and DSPR genomes are available as Supplemental File 4.

\section{Acknowledgements}

We thank Stuart Macdonald (University of Kansas) for providing fly stocks; Christina McHenry and Robert Lyons at the University of Michigan Biomedical Research Core Facilities for assistance with PacBio library preparation and sequencing; Noah Workman, Julia Portocarrero and Magdy Alabady at the University of Georgia Genomics and Bioinformatics Core for assistance with 10x Genomics library preparation and Illumina sequencing; the Georgia Advanced Computing Resource Center for computing time; members of the Bergman Lab for helpful comments throughout the project; and XX for comments on the manuscript. This work was supported by the Human Frontiers of Science (C.M.B.) and Georgia Research Foundation (C.M.B.) and the Howard Hughes Medical Institute (N.P.). 
bioRxiv preprint doi: https://doi.org/10.1101/2022.01.04.471818; this version posted January 4, 2022. The copyright holder for this preprint (which was not certified by peer review) is the author/funder, who has granted bioRxiv a license to display the preprint in perpetuity. It is made available under aCC-BY 4.0 International license.

\section{Literature Cited}

Adey, A., J. N. Burton, J. O. Kitzman, J. B. Hiatt, A. P. Lewis, B. K. Martin, R. Qiu, C. Lee, and J. Shendure, 2013 The haplotyperesolved genome and epigenome of the aneuploid HeLa cancer cell line. Nature 500: 207-211.

Alkan, C., S. Sajjadian, and E. E. Eichler, 2011 Limitations of next-generation genome sequence assembly. Nat Methods 8: 61-65.

Bairu, M. W., A. O. Aremu, and J. Van Staden, 2011 Somaclonal variation in plants: causes and detection methods. Plant Growth Regul 63: 147-173.

Bankevich, A., S. Nurk, D. Antipov, A. A. Gurevich, M. Dvorkin, A. S. Kulikov, V. M. Lesin, S. I. Nikolenko, S. Pham, A. D. Prjibelski, A. V. Pyshkin, A. V. Sirotkin, N. Vyahhi, G. Tesler, M. A. Alekseyev, and P. A. Pevzner, 2012 SPAdes: a new genome assembly algorithm and its applications to single-cell sequencing. Journal of Computational Biology 19: 455-477.

Ben-David, U., B. Siranosian, G. Ha, H. Tang, Y. Oren, K. Hinohara, C. A. Strathdee, J. Dempster, N. J. Lyons, R. Burns, A. Nag, G. Kugener, B. Cimini, P. Tsvetkov, Y. E. Maruvka, R. O'Rourke, A. Garrity, A. A. Tubelli, P. Bandopadhayay, A. Tsherniak, F. Vazquez, B. Wong, C. Birger, M. Ghandi, A. R. Thorner, J. A. Bittker, M. Meyerson, G. Getz, R. Beroukhim, and T. R. Golub, 2018 Genetic and transcriptional evolution alters cancer cell line drug response. Nature 560: 325-330.

Bergman, C. M., H. Quesneville, D. Anxolabehere, and M. Ashburner, 2006 Recurrent insertion and duplication generate networks of transposable element sequences in the Drosophila melanogaster genome. Genome Biol 7: R112.

Berlin, K., S. Koren, C.-S. Chin, J. P. Drake, J. M. Landolin, and A. M. Phillippy, 2015 Assembling large genomes with single-molecule sequencing and locality-sensitive hashing. Nat Biotech 33: 623-630.

Boeva, V., T. Popova, K. Bleakley, P. Chiche, J. Cappo, G. Schleiermacher, I. Janoueix-Lerosey, O. Delattre, and E. Barillot, 2012 Control-FREEC: a tool for assessing copy number and allelic content using next-generation sequencing data. Bioinformatics 28: 423-425.

Bracewell, R., K. Chatla, M. J. Nalley, and D. Bachtrog, 2019 Dynamic turnover of centromeres drives karyotype evolution in Drosophila. eLife 8: e49002.

Bushnell, B., 2014 BBMap: a fast, accurate, splice-aware aligner. Technical Report LBNL-7065E, Lawrence Berkeley National Lab. (LBNL), Berkeley, CA (United States).

Chakraborty, M., J. J. Emerson, S. J. Macdonald, and A. D. Long, 2019 Structural variants exhibit widespread allelic heterogeneity and shape variation in complex traits. Nat Commun 10: 4872.

Chakraborty, M., N. W. VanKuren, R. Zhao, X. Zhang, S. Kalsow, and J. J. Emerson, 2018 Hidden genetic variation shapes the structure of functional elements in Drosophila. Nat Genet 50: 20-25.

Chang, C.-H., A. Chavan, J. Palladino, X. Wei, N. M. C. Martins, B. Santinello, C.-C. Chen, J. Erceg, B. J. Beliveau, C.T. Wu, A. M. Larracuente, and B. G. Mellone, 2019 Islands of retroelements are major components of Drosophila centromeres. PLOS Biology 17: e3000241.

Chen, S., Y. Zhou, Y. Chen, and J. Gu, 2018 fastp: an ultra-fast all-in-one FASTQ preprocessor. Bioinformatics 34: i884-i890.

Chin, C.-S., P. Peluso, F. J. Sedlazeck, M. Nattestad, G. T. Concepcion, A. Clum, C. Dunn, R. O'Malley, R. Figueroa-Balderas, A. Morales-Cruz, G. R. Cramer, M. Delledonne, C. Luo, J. R.
Ecker, D. Cantu, D. R. Rank, and M. C. Schatz, 2016 Phased diploid genome assembly with single-molecule real-time sequencing. Nat Methods 13: 1050-1054.

Chu, C., R. Borges-Monroy, V. V. Viswanadham, S. Lee, H. Li, E. A. Lee, and P. J. Park, 2021 Comprehensive identification of transposable element insertions using multiple sequencing technologies. Nat Commun 12: 3836.

Cridland, J. M., S. J. Macdonald, A. D. Long, and K. R. Thornton, 2013 Abundance and distribution of transposable elements in two Drosophila QTL mapping resources. Mol Biol Evol 30: 2311-2327.

Dias, G. B., M. A. Altammami, H. A. F. El-Shafie, F. M. Alhoshani, M. B. Al-Fageeh, C. M. Bergman, and M. M. Manee, 2021 Haplotype-resolved genome assembly enables gene discovery in the red palm weevil Rhynchophorus ferrugineus. Scientific Reports 11: 9987.

Disdero, E. and J. Filee, 2017 LoRTE: Detecting transposoninduced genomic variants using low coverage PacBio long read sequences. Mob DNA 8: 5 .

Echalier, G., 1997 Drosophila Cells in Culture. Academic Press, San Diego, Calif.

Ellison, C. E. and W. Cao, 2020 Nanopore sequencing and Hi-C scaffolding provide insight into the evolutionary dynamics of transposable elements and piRNA production in wild strains of Drosophila melanogaster. Nucleic Acids Res 48: 290-303.

Ewing, A. D., N. Smits, F. J. Sanchez-Luque, J. Faivre, P. M. Brennan, S. R. Richardson, S. W. Cheetham, and G. J. Faulkner, 2020 Nanopore Sequencing Enables Comprehensive Transposable Element Epigenomic Profiling. Molecular Cell .

Ford, D. K. and G. Yerganian, 1958 Observations on the chromosomes of Chinese hamster cells in tissue culture. J Natl Cancer Inst 21: 393-425.

Gremme, G., S. Steinbiss, and S. Kurtz, 2013 GenomeTools: a comprehensive software library for efficient processing of structured genome annotations. IEEE/ACM Transactions on Computational Biology and Bioinformatics 10: 645-656.

Han, S., P. J. Basting, G. B. Dias, A. Luhur, A. C. Zelhof, and C. M. Bergman, 2021a Transposable element profiles reveal cell line identity and loss of heterozygosity in Drosophila cell culture. Genetics 219: iyab113.

Han, S., G. B. Dias, P. J. Basting, M. G. Nelson, S. Patel, M. Marzo, and C. M. Bergman, 2021b Ongoing transposition in cell culture reveals the phylogeny of diverse Drosophila S2 sub-lines. bioRxiv p. 2021.12.08.471819.

Hemmer, L. W., G. B. Dias, B. Smith, K. Van Vaerenberghe, A. Howard, C. M. Bergman, and J. P. Blumenstiel, 2020 Hybrid dysgenesis in Drosophila virilis results in clusters of mitotic recombination and loss-of-heterozygosity but leaves meiotic recombination unaltered. Mob DNA 11: 10.

Hink, W., 1976 A compilation of invertebrate cell lines and culture media. In Invertebrate Tissue Culture, edited by K. Maramorosch, pp. 319-369, Academic Press.

Hoskins, R. A., J. W. Carlson, K. H. Wan, S. Park, I. Mendez, S. E. Galle, B. W. Booth, B. D. Pfeiffer, R. A. George, R. Svirskas, M. Krzywinski, J. Schein, M. C. Accardo, E. Damia, G. Messina, M. Méndez-Lago, B. de Pablos, O. V. Demakova, E. N. Andreyeva, L. V. Boldyreva, M. Marra, A. B. Carvalho, P. Dimitri, A. Villasante, I. F. Zhimulev, G. M. Rubin, G. H. Karpen, and S. E. Celniker, 2015 The Release 6 reference sequence of the Drosophila melanogaster genome. Genome Res 25: 445-458.

Ilyin, Y. V., V. G. Chmeliauskaite, E. V. Ananiev, and G. P. Georgiev, 1980 Isolation and characterization of a new family 
bioRxiv preprint doi: https://doi.org/10.1101/2022.01.04.471818; this version posted January 4, 2022. The copyright holder for this preprint (which was not certified by peer review) is the author/funder, who has granted bioRxiv a license to display the preprint in perpetuity. It is made available under aCC-BY 4.0 International license.

of mobile dispersed genetic elements, mdg3, in Drosophila melanogaster. Chromosoma 81: 27-53.

Jiang, T., B. Liu, J. Li, and Y. Wang, 2019 rMETL: sensitive mobile element insertion detection with long read realignment. Bioinformatics 35: 3484-3486.

Katoh, K. and D. M. Standley, 2013 MAFFT multiple sequence alignment software version 7: improvements in performance and usability. Mol Biol Evol 30: 772-780.

Kelley, D. R. and S. L. Salzberg, 2010 Detection and correction of false segmental duplications caused by genome mis-assembly. Genome Biol 11: R28.

King, E. G., C. M. Merkes, C. L. McNeil, S. R. Hoofer, S. Sen, K. W. Broman, A. D. Long, and S. J. Macdonald, 2012 Genetic dissection of a model complex trait using the Drosophila Synthetic Population Resource. Genome Res 22: 1558-1566.

Kirov, I., P. Merkulov, M. Dudnikov, E. Polkhovskaya, R. A. Komakhin, Z. Konstantinov, S. Gvaramiya, A. Ermolaev, N. Kudryavtseva, M. Gilyok, M. G. Divashuk, G. I. Karlov, and A. Soloviev, 2021 Transposons hidden in Arabidopsis thaliana genome assembly gaps and mobilization of non-autonomous LTR retrotransposons unravelled by nanotei pipeline. Plants 10: 2681.

Kolmogorov, M., J. Yuan, Y. Lin, and P. A. Pevzner, 2019 Assembly of long, error-prone reads using repeat graphs. Nature Biotechnology 37: 540-546.

Koren, S., B. P. Walenz, K. Berlin, J. R. Miller, N. H. Bergman, and A. M. Phillippy, 2017 Canu: scalable and accurate long-read assembly via adaptive k-mer weighting and repeat separation. Genome Res 27: 722-736.

Kosugi, S., Y. Momozawa, X. Liu, C. Terao, M. Kubo, and Y. Kamatani, 2019 Comprehensive evaluation of structural variation detection algorithms for whole genome sequencing. Genome Biol 20: 117.

Kriventseva, E. V., D. Kuznetsov, F. Tegenfeldt, M. Manni, R. Dias, F. A. Simão, and E. M. Zdobnov, 2019 OrthoDB v10: sampling the diversity of animal, plant, fungal, protist, bacterial and viral genomes for evolutionary and functional annotations of orthologs. Nucleic Acids Res 47: D807-D811.

Lee, H., C. J. McManus, D.-Y. Cho, M. Eaton, F. Renda, M. P. Somma, L. Cherbas, G. May, S. Powell, D. Zhang, L. Zhan, A. Resch, J. Andrews, S. E. Celniker, P. Cherbas, T. M. Przytycka, M. Gatti, B. Oliver, B. Graveley, and D. MacAlpine, 2014 DNA copy number evolution in Drosophila cell lines. Genome Biol 15: R70.

Li, H., 2018 Minimap2: pairwise alignment for nucleotide sequences. Bioinformatics 34: 3094-3100.

Liu, Y., Y. Mi, T. Mueller, S. Kreibich, E. G. Williams, A. Van Drogen, C. Borel, M. Frank, P.-L. Germain, I. Bludau, M. Mehnert, M. Seifert, M. Emmenlauer, I. Sorg, F. Bezrukov, F. S. Bena, H. Zhou, C. Dehio, G. Testa, J. Saez-Rodriguez, S. E. Antonarakis, W.-D. Hardt, and R. Aebersold, 2019 Multi-omic measurements of heterogeneity in HeLa cells across laboratories. Nat Biotechnol 37: 314-322.

Maisonhaute, C., D. Ogereau, A. Hua-Van, and P. Capy, 2007 Amplification of the 1731 LTR retrotransposon in Drosophila melanogaster cultured cells: origin of neocopies and impact on the genome. Gene 393: 116-126.

Manee, M. M., J. Jackson, and C. M. Bergman, 2018 Conserved noncoding elements influence the transposable element landscape in Drosophila. Genome Biol Evol 10: 1533-1545.

Mariyappa, D., D. B. Rusch, S. Han, A. Luhur, D. Overton, D. F. B. Miller, C. M. Bergman, and A. C. Zelhof, 2021 A novel trans- posable element based authentication protocol for Drosophila cell lines. G3 p. (in press).

Meyers, L. A. and D. A. Levin, 2006 On the abundance of polyploids in flowering plants. Evolution 60: 1198-1206.

Miller, J. R., S. Koren, K. A. Dilley, D. M. Harkins, T. B. Stockwell, R. S. Shabman, and G. G. Sutton, 2018a A draft genome sequence for the Ixodes scapularis cell line, ISE6. F1000Res 7.

Miller, J. R., S. Koren, K. A. Dilley, V. Puri, D. M. Brown, D. M. Harkins, F. Thibaud-Nissen, B. Rosen, X.-G. Chen, Z. Tu, I. V. Sharakhov, M. V. Sharakhova, R. Sebra, T. B. Stockwell, N. H. Bergman, G. G. Sutton, A. M. Phillippy, P. M. Piermarini, and R. S. Shabman, 2018b Analysis of the Aedes albopictus C6/36 genome provides insight into cell line utility for viral propagation. Gigascience 7: 1-13.

Miller, S. A., D. D. Dykes, and H. F. Polesky, 1988 A simple salting out procedure for extracting DNA from human nucleated cells. Nucleic Acids Res 16: 1215-1215.

Minh, B. Q., H. A. Schmidt, O. Chernomor, D. Schrempf, M. D. Woodhams, A. von Haeseler, and R. Lanfear, 2020 IQ-TREE 2: New models and efficient methods for phylogenetic Inference in the genomic era. Molecular Biology and Evolution 37: 15301534 .

Miyao, A., M. Nakagome, T. Ohnuma, H. Yamagata, H. Kanamori, Y. Katayose, A. Takahashi, T. Matsumoto, and H. Hirochika, 2012 Molecular spectrum of somaclonal variation in regenerated rice revealed by whole-genome sequencing. Plant Cell Physiol 53: 256-264.

Mohamed, M., N. T.-M. Dang, Y. Ogyama, N. Burlet, B. Mugat, M. Boulesteix, V. Merel, P. Veber, J. Salces-Ortiz, D. Severac, A. Pelisson, C. Vieira, F. Sabot, M. Fablet, and S. Chambeyron, 2020 A transposon story: from te content to te dynamic invasion of drosophila genomes using the single-molecule sequencing technology from oxford nanopore. Cells 9: 1776.

Nattestad, M., S. Goodwin, K. Ng, T. Baslan, F. J. Sedlazeck, P. Rescheneder, T. Garvin, H. Fang, J. Gurtowski, E. Hutton, E. Tseng, C.-S. Chin, T. Beck, Y. Sundaravadanam, M. Kramer, E. Antoniou, J. D. McPherson, J. Hicks, W. R. McCombie, and M. C. Schatz, 2018 Complex rearrangements and oncogene amplifications revealed by long-read DNA and RNA sequencing of a breast cancer cell line. Genome Res 28: 1126-1135.

Nelson, M. G., R. S. Linheiro, and C. M. Bergman, 2017 McClintock: an integrated pipeline for detecting transposable element insertions in whole-genome shotgun sequencing data. G3 7: 2749-2762.

Ogura, H., 1990 Chromosome variation in plant tissue culture. In Somaclonal Variation in Crop Improvement I, edited by Y. P. S. Bajaj, Biotechnology in Agriculture and Forestry, pp. 49-84, Springer, Berlin, Heidelberg.

Peona, V., M. P. K. Blom, L. Xu, R. Burri, S. Sullivan, I. Bunikis, I. Liachko, T. Haryoko, K. A. Jønsson, Q. Zhou, M. Irestedt, and A. Suh, 2021 Identifying the causes and consequences of assembly gaps using a multiplatform genome assembly of a bird-of-paradise. Mol Ecol Resour 21: 263-286.

Potter, S. S., W. J. Brorein, P. Dunsmuir, and G. M. Rubin, 1979 Transposition of elements of the 412, copia and 297 dispersed repeated gene families in Drosophila. Cell 17: 415-427.

Quinlan, A. R. and I. M. Hall, 2010 BEDTools: a flexible suite of utilities for comparing genomic features. Bioinformatics $\mathbf{2 6}$ : 841-842.

Rahman, R., G.-w. Chirn, A. Kanodia, Y. A. Sytnikova, B. Brembs, C. M. Bergman, and N. C. Lau, 2015 Unique transposon landscapes are pervasive across Drosophila melanogaster genomes. 
bioRxiv preprint doi: https://doi.org/10.1101/2022.01.04.471818; this version posted January 4, 2022. The copyright holder for this preprint (which was not certified by peer review) is the author/funder, who has granted bioRxiv a license to display the preprint in perpetuity. It is made available under aCC-BY 4.0 International license.

Nucleic Acids Res 43: 10655-10672.

Rhie, A., S. A. McCarthy, O. Fedrigo, J. Damas, G. Formenti, S. Koren, M. Uliano-Silva, W. Chow, A. Fungtammasan, J. Kim, C. Lee, B. J. Ko, M. Chaisson, G. L. Gedman, L. J. Cantin, F. Thibaud-Nissen, L. Haggerty, I. Bista, M. Smith, B. Haase, J. Mountcastle, S. Winkler, S. Paez, J. Howard, S. C. Vernes, T. M. Lama, F. Grutzner, W. C. Warren, C. N. Balakrishnan, D. Burt, J. M. George, M. T. Biegler, D. Iorns, A. Digby, D. Eason, B. Robertson, T. Edwards, M. Wilkinson, G. Turner, A. Meyer, A. F. Kautt, P. Franchini, H. W. Detrich, H. Svardal, M. Wagner, G. J. P. Naylor, M. Pippel, M. Malinsky, M. Mooney, M. Simbirsky, B. T. Hannigan, T. Pesout, M. Houck, A. Misuraca, S. B. Kingan, R. Hall, Z. Kronenberg, I. Sović, C. Dunn, Z. Ning, A. Hastie, J. Lee, S. Selvaraj, R. E. Green, N. H. Putnam, I. Gut, J. Ghurye, E. Garrison, Y. Sims, J. Collins, S. Pelan, J. Torrance, A. Tracey, J. Wood, R. E. Dagnew, D. Guan, S. E. London, D. F. Clayton, C. V. Mello, S. R. Friedrich, P. V. Lovell, E. Osipova, F. O. Al-Ajli, S. Secomandi, H. Kim, C. Theofanopoulou, M. Hiller, Y. Zhou, R. S. Harris, K. D. Makova, P. Medvedev, J. Hoffman, P. Masterson, K. Clark, F. Martin, K. Howe, P. Flicek, B. P. Walenz, W. Kwak, H. Clawson, M. Diekhans, L. Nassar, B. Paten, R. H. S. Kraus, A. J. Crawford, M. T. P. Gilbert, G. Zhang, B. Venkatesh, R. W. Murphy, K.-P. Koepfli, B. Shapiro, W. E. Johnson, F. Di Palma, T. Marques-Bonet, E. C. Teeling, T. Warnow, J. M. Graves, O. A. Ryder, D. Haussler, S. J. O'Brien, J. Korlach, H. A. Lewin, K. Howe, E. W. Myers, R. Durbin, A. M. Phillippy, and E. D. Jarvis, 2021 Towards complete and error-free genome assemblies of all vertebrate species. Nature 592: 737-746.

Ruan, J. and H. Li, 2020 Fast and accurate long-read assembly with wtdbg2. Nat Methods 17: 155-158.

Sackton, T. B., R. J. Kulathinal, C. M. Bergman, A. R. Quinlan, E. B. Dopman, M. Carneiro, G. T. Marth, D. L. Hartl, and A. G. Clark, 2009 Population genomic inferences from sparse high-throughput sequencing of two populations of Drosophila melanogaster. Genome Biol Evol 1: 449-65.

Schneider, I., 1972 Cell lines derived from late embryonic stages of Drosophila melanogaster. J Embryol Exp Morphol 27: 353365.

Sedlazeck, F. J., P. Rescheneder, M. Smolka, H. Fang, M. Nattestad, A. von Haeseler, and M. C. Schatz, 2018 Accurate detection of complex structural variations using single-molecule sequencing. Nat Methods 15: 461-468.

Simao, F. A., R. M. Waterhouse, P. Ioannidis, E. V. Kriventseva, and E. M. Zdobnov, 2015 BUSCO: assessing genome assembly and annotation completeness with single-copy orthologs. Bioinformatics 31: 3210-3212.

Talsania, K., M. Mehta, C. Raley, Y. Kriga, S. Gowda, C. Grose, M. Drew, V. Roberts, K. T. Cheng, S. Burkett, S. Oeser, R. Stephens, D. Soppet, X. Chen, P. Kumar, O. German, T. Smirnova, C. Hautman, J. Shetty, B. Tran, Y. Zhao, and D. Esposito, 2019 Genome assembly and annotation of the Trichoplusia ni Tni-FNL insect cell line enabled by long-read technologies. Genes (Basel) 10.

Tattini, L., R. D'Aurizio, and A. Magi, 2015 Detection of genomic structural variants from next-generation sequencing data. Front Bioeng Biotechnol 3: 92.

Todd, R. T., A. Forche, and A. Selmecki, 2017 Ploidy variation in fungi: polyploidy, aneuploidy, and genome evolution. Microbiology Spectrum 5: 5.4.09.

Waterhouse, R. M., M. Seppey, F. A. Simão, M. Manni, P. Ioannidis, G. Klioutchnikov, E. V. Kriventseva, and E. M. Zdobnov,
2018 BUSCO applications from quality assessments to gene prediction and phylogenomics. Mol Biol Evol 35: 543-548.

Weisenfeld, N. I., V. Kumar, P. Shah, D. M. Church, and D. B. Jaffe, 2017 Direct determination of diploid genome sequences. Genome Res 27: 757-767.

Wierzbicki, F., F. Schwarz, O. Cannalonga, and R. Kofler, 2021 Novel quality metrics allow identifying and generating highquality assemblies of piRNA clusters. Mol Ecol Resour p. (in press).

Yanagawa, S., J. S. Lee, and A. Ishimoto, 1998 Identification and characterization of a novel line of Drosophila Schneider S2 cells that respond to wingless signaling. J Biol Chem 273: 32353-32359.

Zhang, Y., J. H. Malone, S. K. Powell, V. Periwal, E. Spana, D. M. Macalpine, and B. Oliver, 2010 Expression in aneuploid Drosophila S2 cells. PLOS biology 8: e1000320+.

Zhao, X., R. L. Collins, W.-P. Lee, A. M. Weber, Y. Jun, Q. Zhu, B. Weisburd, Y. Huang, P. A. Audano, H. Wang, M. Walker, C. Lowther, J. Fu, M. B. Gerstein, S. E. Devine, T. Marschall, J. O. Korbel, E. E. Eichler, M. J. P. Chaisson, C. Lee, R. E. Mills, H. Brand, and M. E. Talkowski, 2021 Expectations and blind spots for structural variation detection from long-read assemblies and short-read genome sequencing technologies. The American Journal of Human Genetics 108: 919-928.

Zheng, G. X. Y., B. T. Lau, M. Schnall-Levin, M. Jarosz, J. M. Bell, C. M. Hindson, S. Kyriazopoulou-Panagiotopoulou, D. A. Masquelier, L. Merrill, J. M. Terry, P. A. Mudivarti, P. W. Wyatt, R. Bharadwaj, A. J. Makarewicz, Y. Li, P. Belgrader, A. D. Price, A. J. Lowe, P. Marks, G. M. Vurens, P. Hardenbol, L. Montesclaros, M. Luo, L. Greenfield, A. Wong, D. E. Birch, S. W. Short, K. P. Bjornson, P. Patel, E. S. Hopmans, C. Wood, S. Kaur, G. K. Lockwood, D. Stafford, J. P. Delaney, I. Wu, H. S. Ordonez, S. M. Grimes, S. Greer, J. Y. Lee, K. Belhocine, K. M. Giorda, W. H. Heaton, G. P. McDermott, Z. W. Bent, F. Meschi, N. O. Kondov, R. Wilson, J. A. Bernate, S. Gauby, A. Kindwall, C. Bermejo, A. N. Fehr, A. Chan, S. Saxonov, K. D. Ness, B. J. Hindson, and H. P. Ji, 2016 Haplotyping germline and cancer genomes with high-throughput linked-read sequencing. Nature Biotechnology 34: 303-311.

Zhou, B., S. S. Ho, S. U. Greer, N. Spies, J. M. Bell, X. Zhang, X. Zhu, J. G. Arthur, S. Byeon, R. Pattni, I. Saha, Y. Huang, G. Song, D. Perrin, W. H. Wong, H. P. Ji, A. Abyzov, and A. E. Urban, 2019a Haplotype-resolved and integrated genome analysis of the cancer cell line HepG2. Nucleic Acids Res 47: 3846-3861.

Zhou, B., S. S. Ho, S. U. Greer, X. Zhu, J. M. Bell, J. G. Arthur, N. Spies, X. Zhang, S. Byeon, R. Pattni, N. Ben-Efraim, M. S. Haney, R. R. Haraksingh, G. Song, H. P. Ji, D. Perrin, W. H. Wong, A. Abyzov, and A. E. Urban, 2019b Comprehensive, integrated, and phased whole-genome analysis of the primary ENCODE cell line K562. Genome Res 29: 472-484.

Zhou, W., S. B. Emery, D. A. Flasch, Y. Wang, K. Y. Kwan, J. M. Kidd, J. V. Moran, and R. E. Mills, 2020 Identification and characterization of occult human-specific LINE-1 insertions using long-read sequencing technology. Nucleic Acids Res 48: 1146-1163.

Zhuang, J., J. Wang, W. Theurkauf, and Z. Weng, 2014 TEMP: a computational method for analyzing transposable element polymorphism in populations. Nucleic Acids Res 42: 68266838. 